\title{
Nora's lesion: bizarre parosteal osteochondromatous proliferation in right foot: a case report
}

\author{
Shikhar Yadav*, Divya G., Jithin Mohan, Joice Varghese
}

Department of Orthopaedics, Lourdes Hospital, Ernakulam, Kerala, India

Received: 05 July 2021

Accepted: 13 August 2021

\section{*Correspondence:}

Dr. Shikhar Yadav,

E-mail: dr.shikhar.yadav@gmail.com

Copyright: (c) the author(s), publisher and licensee Medip Academy. This is an open-access article distributed under the terms of the Creative Commons Attribution Non-Commercial License, which permits unrestricted non-commercial use, distribution, and reproduction in any medium, provided the original work is properly cited.

\begin{abstract}
Nora's lesion is a benign lesion involving mainly the proximal phalanges, metatarsals or metacarpals in the hands and feet. It may be easily confused with a malignant entity and was first identified and reported by Nora et al. in 1983 . We present a case of a 12 years old female with complains of a swelling over the right foot noticed 4 months ago. Plain radiograph revealed heterotrophic calcification over the dorso-lateral aspect of the head of the first metatarsal. MRI scan of the foot was suggestive of a benign pathology with a differential of bizarre parosteal osteochondromatous proliferation (BPOP) or an osteochondroma. The patient was managed with excision biopsy and lesion was excised along with the pseudo-capsule and adjoining periosteum. Cortex appeared normal and wound was washed with hydrogen peroxide and incision closed. Histopathology report was suggestive of Nora's lesion. One year follow up of the patient showed no recurrence. BPOP proliferation is a benign lesion however differentials need to be kept in mind and treatment with excision of the lesion along with the pseudo-capsule and periosteal tissue beneath the lesion has low rates of recurrence.
\end{abstract}

Keywords: Nora's lesion, Bizarre parosteal osteochondromatous proliferation, Heterotrophic calcification, Foot swelling

\section{INTRODUCTION}

Nora's lesion was first identified by Nora et al in the year 1983 when he reported 35 cases involving the hands and feet mostly involving proximal phalanges, metatarsals or metacarpals. ${ }^{1}$ It is a benign lesion which may easily be confused with a malignant entity owing to its aggressive histopathological picture and high rate of recurrence. Very few cases have been reported worldwide since its discovery.

\section{CASE REPORT}

A 12 years old female presented to the out-patient department with complains of a swelling over the right foot which was noticed 4 months ago. There was no history of trauma, pain, fever or any other associated swelling. On examination, a well-defined swelling was seen over the dorsum of right foot between the first metatarsal web space measuring $3 \times 2 \mathrm{~cm}$. On palpation it was hard in consistency with smooth surface and well-defined margins and was attached to the underlying bone. There was no local rise of temperature or tenderness around the region.

Plain radiograph of the right foot revealed heterotrophic calcification over the dorso-lateral aspect of the head of the first metatarsal (Figure 1). There was no continuity of the mass with the underlying bone and there was no periosteal reaction and no cortical irregularity. A differential diagnosis of ectopic calcification or a neoplastic lesion was made and MRI scan of the foot was advised. MRI scan of foot showed a well-defined irregularly shaped mildly enhancing altered signal intensity lesion with blooming involving lateral juxta cortical surface of head of first metatarsal bone with no evidence of extension of lesion 
into the first metatarsophalangeal joint (Figure 2). The features were suggestive of a benign pathology and possible differential diagnosis included bizarre parosteal osteochondromatous proliferation (BPOP) or an osteochondroma was made. The patient was then planned for an excision biopsy. The patient was positioned and incision was made centred over the swelling. Soft tissue was dissected and the lesion was identified which was found to be multilobulated (Figure 3). It was not adhered to the surrounding soft tissue and was dissected and excised along with the pseudocapsule (Figure 4). The underlying cortex appeared normal (Figure 5). A discontinuity in the periosteum was evident and its edges were freshened and the site was thoroughly washed using hydrogen peroxide and incision closed.

Histopathological examination of the mass showed a lesion composed of disorganized cellular cartilage with patchy ossification, calcification and maturation into disorganized bone (Figure 6). Proliferation of fibroblasts were seen surrounding the lesion and occupying intertrabecular space. Cartilage was cellular and showed enlarged, bizarre and some binucleated chondrocytes with maturation into bone. A deep blue staining of mineralized cartilaginous matrix was seen which was suggestive of BPOP. One year follow up of the patient showed no recurrence of the lesion. Consent was taken by the parents and the patient for publication.

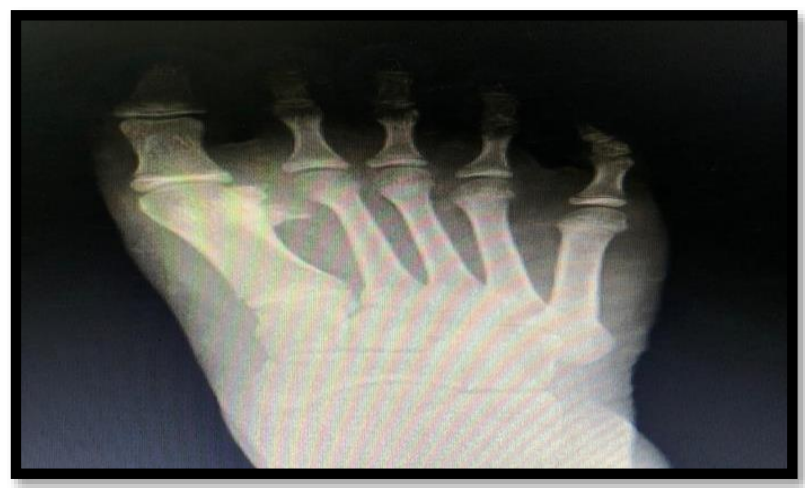

Figure 1: Plain radiograph showing heterotrophic calcification near the head of first metatarsal.

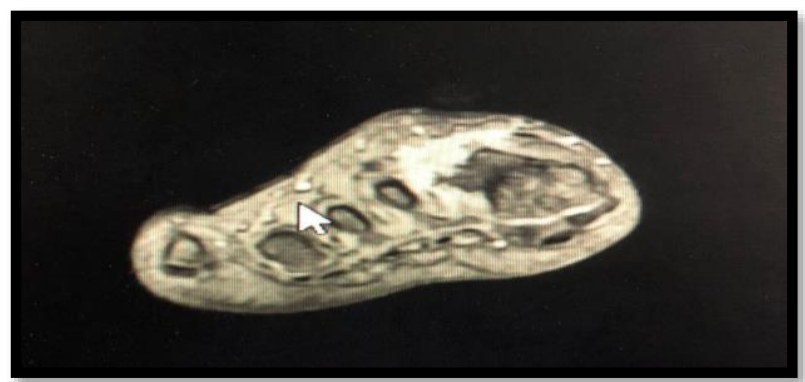

Figure 2: MRI scan showing lesion arising from the cortex of first metatarsal with no continuity of the medullary cavity.

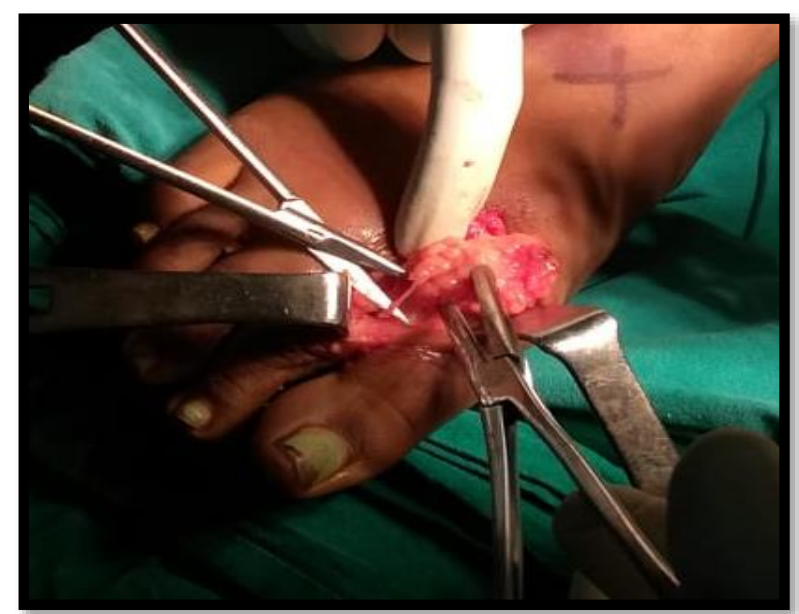

Figure 3: Multilobulated lesion arising from the cortex of first metatarsal with no adhesions to surrounding soft tissue.

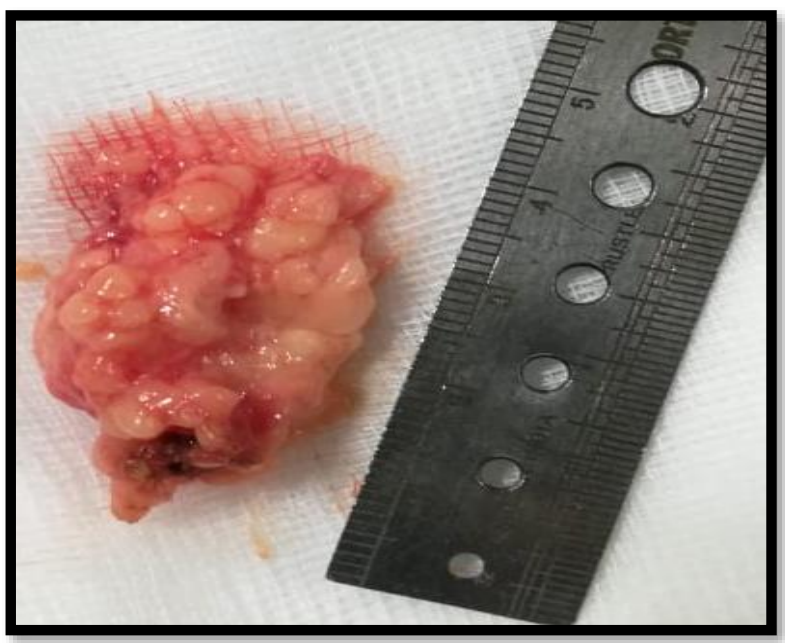

Figure 4: Excised multilobulated lesion.

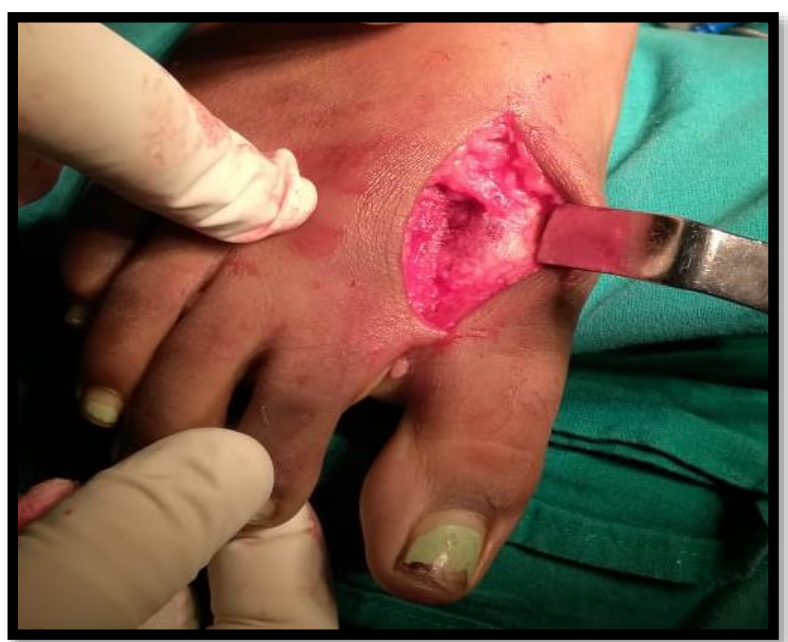

Figure 5: After excision of the mass along with the periosteal tissue. 


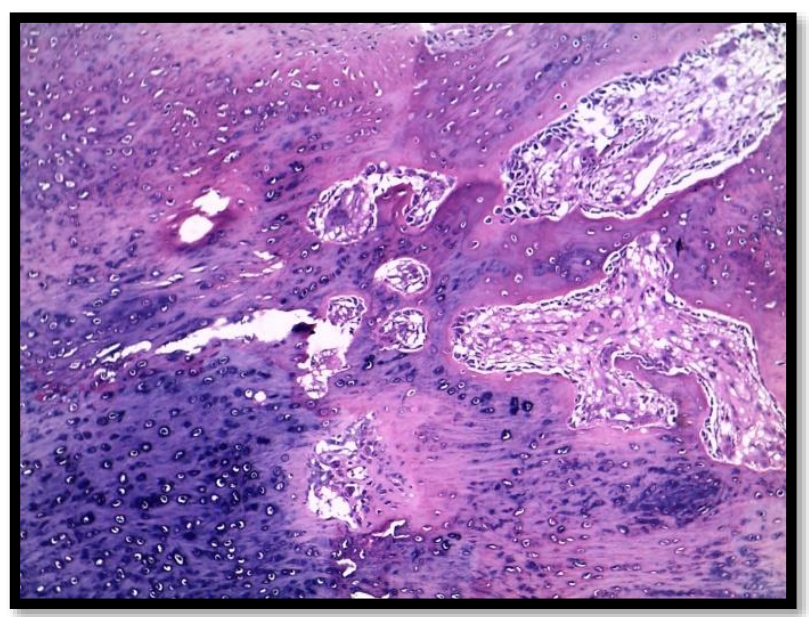

Figure 6: Histopathological picture showing bone, cartilage and fibrous tissue.

\section{DISCUSSION}

Nora et al in 1983 reported 35 cases with peripheral skeletal osteochondromatous tumefactions which were both histologically and radiologically distinct and named it BPOP. ${ }^{1}$ The average age group affected by Nora's lesion is 34 with no sex predilection. The differentials to keep in mind which resemble Nora's lesion include benign lesions such as Myositis ossificans, osteochondroma, florid reactive periostitis and periosteal chondroma malignant lesions such as periosteal osteosarcoma, parosteal osteosarcoma and chondrosarcoma. ${ }^{2}$ Nora's lesion can be differentiated with myositis ossificans on histological examination which will show matured ossification at the periphery in myositis ossificans unlike the cartilaginous cap in BPOP. Continuity of the lesion with the parent bone will help differentiate BPOP with osteochondroma which is continuous with the bone and will characteristically have a continuation of the medullary cavity into the lesion. Similarly, florid reactive periostitis would be continuous with the parent bone. Periosteal chondroma will show erosive defects over the cortex wile periosteal osteosarcoma usually involves the long bones and parosteal osteosarcoma are exceedingly rare in hand. ${ }^{3}$

\section{Gross and histology}

Grossly the lesion often measures $0.4-3.0 \mathrm{~cm}$ with a cartilage cap covering the underlying bony matrix. Grossly it often resembles ostochondroma but the differences are evident on histological examination. ${ }^{1}$ Microscopically the lesion is composed of three components- bone, cartilage and fibrous tissue. The cartilage cap is hypercellular and less organized than osteochondroma but lacks hyperchromasia and cytological atypia. ${ }^{4}$ BPOP is characterized by a blue tinctorial stain of irregular calcified cartilage martrix seen at bone-cartilage interface also called as blue bone by Meneses et al. ${ }^{2}$ The bone component is often more organised with bony trabeculae separated by spindle cells forming a loose fibrous tissue stroma. ${ }^{4}$

\section{Radiology}

Radiologically BPOP appears as a heterotrophic calcification arising from the cortex of the underlying bone usually involving the metaphyseal region. The underlying bone remains unaffected and appears normal. The margins are usually well demarcated with no periosteal reactions. ${ }^{1}$ On MRI scans, the lesion shows its characteristic demarcating feature from an osteochondroma which is the absence of continuity of the medullary cavity into the lesion. ${ }^{2}$ On T1 weighted images, the mass is isointense with muscle and on T2 weighted images the surface of the lesions were homogenous in intensity while the deeper parts were heterogenous in intensity. ${ }^{5}$

\section{Cause}

The cause of the lesion is largely unknown and debates have been going on whether to classify it as a reparative process or a neoplasm. Few authors classify Nora's lesion as a progressive form of florid reactive periostitis which may further progress into turret exostosis if left unchecked. ${ }^{6}$ A unitary hypothesis has been postulated to explain the multiple proliferative processes occurring around the phalanges. It states that in initial stimulus often a trauma results in subperiosteal haemorrhage which if contained results in a fusiform periostitis which later develops into florid reactive periostitis.

However, if the periosteum is breached, a lobular lesion is formed with the reactive process extending into the soft tissue and matures to form a BPOP. When this lesion is on the dorsal aspect of the terminal phalanx it can extend into the nail bed which alters its maturation to form a subungual exostosis or if the nail is lost then it forms a turret exostosis. ${ }^{7}$ Meneses et al reported two third of his patients had a history of trauma and Smith et al reported a history of trauma in $71 \%$ of his cases. ${ }^{2,8}$ Horiguchi et al did an immunohistochemical and molecular analysis of BPOP and concluded BPOP to be a reparative process and is similar to endochondral ossification in growth plate. ${ }^{5}$

\section{Treatment}

Treatment of Nora's lesion involves excision of the tumefaction however the lesion is known for its notorious rates of recurrence. Nora et al report a recurrence rate of $51 \%$ after primary excision and Meneses et al reported a recurrence rater of $55 \% .^{1,2}$ Michelsen et al advised excision of the lesion along with the pseudocapsule and periosteal tissue beneath the lesion and any area of the cortex of the bone that appeared to be abnormal. With this technique they reported a $10 \%$ recurrence rate. ${ }^{4}$

\section{CONCLUSION}

BPOP is a benign lesion however differentials need to be kept in mind and treatment with excision of the lesion along with the pseudocapsule and periosteal tissue beneath the lesion has low rates of recurrence. 
Funding: No funding sources

Conflict of interest: None declared

Ethical approval: Not required

\section{REFERENCES}

1. Nora FE, Dahlin DC, Beabout JW. Bizarre parosteal osteochondromatous proliferations of the hands and feet. Am J Surg Pathol. 1983;7(3):245-50.

2. Meneses MF, Unni KK, Swee RG. Bizarre parosteal osteochondromatous proliferation of bone (Nora's lesion). Am J Surg Pathol. 1993;17(7):691-7.

3. Abramovici L, Steiner GC. Bizarre parosteal osteochondromatous proliferation (Nora's lesion): a retrospective study of 12 cases, 2 arising in long bones. Hum Pathol. 2002;33(12):1205-10.

4. Michelsen H, Abramovici L, Steiner G, Posner MA. Bizarre parosteal osteochondromatous proliferation (Nora's lesion) in the hand. J Hand Surg Am. 2004;29(3):520-5.
5. Horiguchi H, Sakane M, Matsui M, Wadano Y. Bizarre parosteal osteochondromatous proliferation (Nora's lesion) of the foot. Pathol Int. 2001;51(10):816-23.

6. Sundaram M, Wang L, Rotman M, Howard R, Saboeiro AP. Florid reactive periostitis and bizarre parosteal osteochondromatous proliferation: prebiopsy imaging evolution, treatment and outcome. Skeletal Radiol. 2001;30(4):192-8.

7. Yuen M, Friedman L, Orr W, Cockshott WP. Proliferative periosteal processes of phalanges: a unitary hypothesis. Skeletal Radiol. 1992;21(5).

8. Smith NC, Ellis AM, Carthy S, Naught P. Bizarre parosteal osteochondromatous proliferation: a review of seven cases. Aust NZJ Surg. 1996;66(10):694-7.

Cite this article as: Yadav S, Divya G, Mohan J, Varghese J. Nora's lesion: bizarre parosteal osteochondromatous proliferation in right foot: a case report. Int J Res Orthop 2021;7:1043-6. 